\title{
Erratum to: Varying the intensity of competition in a multiple prize rent seeking experiment
}

\author{
Lisa R. Anderson • Beth A. Freeborn
}

Published online: 23 December 2009

(C) Springer Science+Business Media, LLC 2009

\section{Erratum to: Public Choice \\ DOI 10.1007/s11127-009-9482-3}

In Anderson and Freeborn (2009) we inadvertently made a coding error in estimating the effects of risk preferences on subjects' rent seeking expenditures.

In models 2 through 5 of Table 5, we include individual specific effects (gender and risk preference as measured by the midpoint of the coefficient of relative risk aversion, hereafter mid-CRRA) and state that we control for individual subject heterogeneity using fixed effects. Econometrically, we cannot include both fixed effects and gender/mid-CRRA; however, a coding error allowed us to generate the results we report. When we correctly account for individual heterogeneity using a random effects model, the coefficients on gender and mid-CRRA are not significant.

However, when we follow Millner and Pratt (1991) by grouping individuals into risk preference categories and performing difference of means tests, there is a significant decrease in overspending relative to the Nash prediction as we move along the risk preference spectrum. Specifically, the four categories are risk loving (mid-CRRA $<-0.15$ ), risk neutral $(-0.15 \leq$ mid-CRRA $<0.15)$, somewhat risk averse $(0.15 \leq$ mid-CRRA $\leq 0.68)$, and very risk averse (mid-CRRA > 0.68). We are guided by Holt and Laury (2002) in separating subjects into the categories of somewhat risk averse and very risk averse. For risk loving individuals, the average deviation from the Nash prediction (calculated as observed effort minus Nash prediction) across all six scenarios is 262.22; for risk neutral, the average deviation is 256.97 ; for somewhat risk averse, the average deviation is 245.35 ; and for very risk averse subjects, the average deviation from the Nash prediction is 190.76 . Table 1 displays

The online version of the original article can be found under doi:10.1007/s11127-009-9482-3.

L.R. Anderson · B.A. Freeborn ( $₫)$

College of William and Mary, Williamsburg, VA 23187, USA

e-mail: bafree@wm.edu 
Table 1 Risk preference and rent seeking behavior

Average subject deviation

from Nash prediction $z$-statistic from

Wilcoxon signed-rank test ( $p$-value)
Risk loving $>$ Risk neutral

Risk neutral $>$ Somewhat risk averse

Somewhat risk averse $>$ Very risk averse
$2.508 * *$

(0.012)

$2.993 * * *$

(0.003)

$2.516 * *$

(0.012)

Notes: $* * *$ and $* * *$ indicate significance at the $10 \%$ level, $5 \%$ level and $1 \%$ level, respectively. For each subject, we calculate the average deviation from the Nash prediction across the six scenarios. The numbers of subjects in each category are: 9 in risk loving, 26 in risk neutral, 63 in somewhat risk averse, and 39 in very risk averse, for a total of 137 subjects. Three subjects are omitted from this analysis due to a missing value for "mid-CRRA" (missing values are generated when subjects make an irrational decision in the lottery choice experiment by choosing a certain low payoff over a certain high payoff)

the relative comparisons of the average deviations across risk categories and the second column reports the $z$-statistic from the Wilcoxon signed-rank test that the deviations are equal. A positive and significant $z$-statistic confirms the statement in the first column. ${ }^{1}$

In summary, the corrected regression analysis shows that the coefficients on gender and mid-CRRA for observed effort are not significant when we control for heterogeneity using random effects and therefore the discussion in the last two paragraphs of Sect. 4.2 (Analysis of individual risk preferences) should be disregarded. There remains evidence, however, that risk preferences impact behavior. Specifically, our results confirm those of Millner and Pratt (1991); more risk averse individuals overspend less relative to the Nash prediction than less risk averse subjects. Thus, the last sentence of the Abstract should now read: "We find significantly less overspending relative to the Nash prediction among more risk averse subjects."

\section{References}

Anderson, L. R., \& Freeborn, B. A. (2009). Varying the intensity of competition in a multiple prize rent seeking experiment. Public Choice doi:10.1007/s11127-009-9482-3.

Holt, C. A., \& Laury, S. K. (2002). Risk aversion and incentive effects. The American Economic Review, 92(5), 1644-1655.

Millner, E. L., \& Pratt, M. D. (1991). Risk aversion and rent-seeking: an extension and some experimental evidence. Public Choice, 69, 81-92.

\footnotetext{
${ }^{1}$ Millner and Pratt (1991) perform t-tests of differences in average effort across 'less risk averse' and 'more risk averse' groups. We take a more conservative approach by using the non-parametric Wilcoxon signedrank test because it does not require an assumption of normality. However, our results also hold when we perform t-tests (t-statistics available upon request).
} 